\title{
Parameter Estimation of Mark-Houwink Equation of Polyethylene Glycol (PEG) Using Molecular Mass and Intrinsic Viscosity in Water
}

\author{
Jean Carlo Rauschkolb ${ }^{1(\mathbb{D})}$, Bruna Caroline Ribeiro ${ }^{1}{ }^{(\mathbb{D})}$, Thais Feiden ${ }^{1(\mathbb{D})}$, Bruno Fischer ${ }^{1(\mathbb{D})}$, Thiago \\ André Weschenfelder ${ }^{1}$ (D), Rogério Luis Cansian ${ }^{1}$ (D), Alexander Junges 1,* (D) \\ 1 Department of Food Engineering, URI -Erechim Av. Sete de Setembro, 1621, Erechim, Rio Grande do Sul, Brazil, 99709- \\ 910, Brazil \\ * Correspondence: junges@uricer.edu.br;
}

Scopus Author ID 18434067000

Received: 8.04.2021; Revised: 12.04.2021; Accepted: 15.05.2021; Published: 10.06.2021

\begin{abstract}
Polyethylene glycol (PEG) is an ingredient for approved drug products by the Food \& Drug Administration. PEG is mostly used as a pharmaceutical adjuvant, ophthalmic and oral acts as an encapsulating agent, plasticizing agent in food packages, modified and/or functionalized materials, among other applications. It is important to know the molecular mass of PEG because it will bring the product configuration for these applications. The use of instrumental techniques is often infeasible due to high investment and operational costs. The viscosimetry by capillary, in the case of a classical technique, simple and inexpensive, allows significant results for the determination of the molecular mass of polymers from the intrinsic viscosity. The objective of the present study was to determine the parameters of the Mark-Houwink equation for PEG using molecular mass and intrinsic viscosity in water at different temperatures. The parameters resulting in " $\mathrm{K}$ " between $0.046828 \times 10^{-3}$ and 0.298291 $\mathrm{x} 10^{-3} \mathrm{~cm}^{3} \cdot \mathrm{g}^{-1}$ and " $\alpha$ " between 0.40 and 0.70 . The viscosimeter by the capillary allowed to obtain significant results for the estimation of the parameters " $K$ " and " $\alpha$ ", with a correlation coefficient greater than $98 \%$.
\end{abstract}

Keywords: Cannon-Fenske; polymer; molecular mass; viscosimetry; polyethylene glycol (PEG).

(C) 2021 by the authors. This article is an open-access article distributed under the terms and conditions of the Creative Commons Attribution (CC BY) license (https://creativecommons.org/licenses/by/4.0/).

\section{Introduction}

Polyethylene glycol (PEG) is an ingredient for approved drug products by the Food \& Drug Administration (FDA, U.S.) [1]. PEG is mostly used as a pharmaceutical adjuvant, ophthalmic and oral acts as an encapsulating agent, plasticizing agent in foods packages, modified and/or functionalized materials [2-15]. The wide availability of molecular mass, which defines the characteristics of the formulations. Due to the presence of groups oxygen ($\mathrm{O}-)$ and hydroxyl $(-\mathrm{OH})$ at some polyethylene glycol molecule $\left(\mathrm{HOCH}_{2} \mathrm{CH}_{2}\left[\mathrm{OCH}_{2} \mathrm{CH}_{2}\right] \mathrm{nOCH}_{2} \mathrm{CH}_{2} \mathrm{OH}\right)$, they are capable of forming connections of hydrogen intra and intermolecular, both connections of hydrogen with several other substances [16]. It is a straight-chain polymer formed by ethylene oxide with one hydroxyl and presents an amphiphilic behavior, as a characteristic of this molecule to have a hydrophilic region and another immiscible region [17]. Among other characteristics, this polymer has very low toxicity, chemically inert, and small environmental risk and can be discarded without previous treatment. 
PEG has a molecular mass between 200 e 4,000,000 Dalton (Da). A PEG between 200 and $600 \mathrm{Da}$ is found in liquid form and above, it has waxy or solid characteristics [18]. Polymers with low molecular mass do not present good tensile strength, while those with very high molecular mass can become brittle. The molecular mass distribution is closely related to the mechanical and physical properties of the polymers, including glass transition temperature and modulus of elasticity [19]. Most of the mechanical, rheological and thermomechanical properties depend on the molecular mass and therefore, the molecular mass of the polymer will influence in its use.

Several studies have reported the influence of the molecular mass of PEG in different applications [20-26]. Moradkhannejhad et al. [27] studied the preparation of poly (lactic acid) (PLA) nanofibers loaded with curcumin using the electrospinning technique. The hydrophilicity of the nanofibers was modified by the addition of poly (ethylene glycol) (PEG) with a molecular mass of 1500 in different mass $(0,5,10,15$ and $20 \%$ by weight in relation to the PLA content) and also by the addition of PEG with different molecular mass $(6000,3350$, $1500,600,400)$ in the same content of $10 \%$ by weight in relation to the PLA content. The results showed that the drug release was intensified with a decrease in the molecular weight of PEG and an increase in the content of PEG.

Faradilla et al. [28] investigated the effects of the molecular weight (MW) of polyethylene glycol (PEG) and the interaction of PEG with nanofillers (nano clay and graphene oxide) on the properties of banana pseudocaule nanocellulose films. PEG MW significantly affected the properties of the films. Low MW PEGs (400 and $1000 \mathrm{~g}$. mol-1) had better interaction with nanocellulose than the PEG with higher MW and improved the flexibility of the films by about $100 \%$. The interaction between PEG1000 and nanofillers significantly modified the properties of composite films. PEG1000 had a good interaction with the nano clay, which was reflected in the formation of nano clay interleaved in the cellulose matrix.

Sun et al. [29] evaluated the effect of the molecule weight (MW) of PEG (MW 2,000; 4,$000 ; 6,000 ; 8,000 ; 10,000$ and 20,000), in the properties of the physical hydrogels based on chitosan. The study showed that the interaction between PEG and other components in the physically cross-linked hydrogels became stronger as the MW of the PEG increased. The study indicated that the crystallinity of the physical hydrogels decreased with an increase in the MW of PEG. It also revealed that the crystallisability of physical hydrogels was first reduced with an increase in the MW of PEG, but then slightly increased with an additional increase in the MW of PEG. Therefore, the MW of PEG played a key role in controlling the ownership of chitosan-based physical hydrogels.

Different instrumental techniques like analysis of terminal groups, colligative properties, scattering light, ultracentrifugation, gel permeation chromatography (GPC) have been used to determine the molecular mass, however, these techniques need high investment and operating cost. Classical techniques using capillary viscosimeters present results consistent with the analytical techniques, allowing scientific research with a high degree of reliability and lower investment cost [30]. Polymers with high molecular weight have higher viscosity in solution due to increased entanglement in the chain. The average molecular weight of the viscosity of the polymers can be calculated from the linear relationship between the molecular weight and the intrinsic viscosity, which can be observed in dilute polymer solutions [31, 32]. Capillary Viscosimetry has been the most popular technique for determining the degree of polymerization and the mean molecular mass of viscosity. This is mainly because it does not need advanced and expensive equipment. The procedure is relatively simple and fast, and the 
method specified by industry standards specifies the method. Most methods for determining molecular mass use polymers in solution, however, reticulated polymers are not soluble in any solvent, and their molecular mass cannot be determined, assuming as infinite molecular mass.

Viscosity by capillary Cannon-Fenske Routine allows significant results for the determination of the intrinsic viscosity. And this provides results for the molecular weight determination of many polymers because it is a simple and low cost. Researchers who do not have access to sophisticated equipment such as GPC due to its high cost can obtain the average viscosimetric molecular mass of an unknown PEG sample, analyzing its intrinsic viscosity in distilled water and applying the Mark-Houwink equation.

By measuring the intrinsic viscosity of polymer solutions, the polymer average molecular weight can be predicted through the Mark-Houwink empirical equation. The equation is one of the most fundamental in the characterization of polymers, relating the intrinsic viscosity of polymer to its molecular mass, with the parameters " $K$ " and " $\alpha$ " that reflect a contribution where " $K$ " is essentially related to flexibility of the intrinsic chain, including the orientation of the constituents, while the exponent " $\alpha$ " reflects the geometric chain [33-35]. Thus, the present study aimed to estimate the parameters of the Mark-Houwink equation from the variation of the viscosity of the polyethylene glycol in water, using five molecular masses in different temperatures.

\section{Materials and Methods}

Polyethylene glycols used for parameter estimation of the Mark-Houwink equation were PEG1500 (1500: molecular mass) (Merk Millipore - Germany), PEG4000 (4000: molecular mass) (Viafarma - Brazil), PEG6000 (6000: molecular mass) (Synth - Brazil), PEG8000 (8000 molecular mass) (Sigma Aldrich - Germany) e PEG10000 (10000: molecular mass) (Fluka - Germany). Reagents used separately for polyethylene glycol solubilization were ethanol (99.9\%, Merck Millipore - Germany), acetone (99.5\%, Synth - Brazil) and distilled water obtained through the reverse osmosis water purifier (Gehaka OS10LXE - Brazil).

\subsection{Characterization of PEG.}

The X-Ray diffraction patterns (XRD) for all PEG samples were performed in a Diffractometer (Rigaku Miniflex II Desktop X-Ray Diffractometer - Japan), using Cu k-alpha radiation $(\lambda=1.5406 \AA)$. The data were collected in a range of $2 \theta$ between $0-70^{\circ}$ using a step of $5 \% \mathrm{~min}$.

\subsection{Methods.}

Concentrations of 100 g.L. $\mathrm{L}^{-1}$ of each of the PEG molecular masses were prepared, and from these, the remaining concentrations of $\left(80,60,40,20,10 \mathrm{~g} . \mathrm{L}^{-1}\right)$ were prepared, as well as a solution containing only the solvent used for solubilization. All concentrations were analyzed at the different temperatures studied, as shown in Table 1.

Table 1. Variables studies.

\begin{tabular}{c|c} 
Molecular Mass (Da) & $1500 ; 4000 ; 6000 ; 8000 ; 10000$ \\
\hline Temperature (K) & $293 ; 298 ; 303 ; 313 ; 323$ \\
\hline Concentration $\left(\right.$ g.L L $\left.^{-1}\right)$ & Zero; $10 ; 20 ; 40 ; 60 ; 80 ; 100$
\end{tabular}




\subsection{Density and viscosity analysis.}

The density determination was measured using a densimeter (Anton Paar DMA 4500; Paar Scientific Ltd., London, UK) and the determination of PEG viscosity was performed through the Cannon-Fenske Routine viscometer (Lauda - Germany) with a capillary diameter of $0.63 \mathrm{~mm}$ using concentrations in the range of 0-100 g.L.-1 and temperature in a range of 293323 K. For viscosity analysis, a transparent bath with water circulation and controlled temperature was used. Each concentration was analyzed individually, where $15 \mathrm{~mL}$ of sample form was transferred to the capillary Viscometer and analyzed in 4 replications to decrease the experimental error.

For a capillary viscosimeter, the viscosity will be the only function of the density of the solution and the draining time in the capillary [35,36]. From the time flow of the fluid in the viscosimeter and density is calculated the relative viscosity $\left(\boldsymbol{\eta}_{\boldsymbol{r}}\right)$, represented by Equation (1):

$$
\boldsymbol{\eta}_{\boldsymbol{r}}=(\boldsymbol{t} . \boldsymbol{\rho}) /\left(\boldsymbol{t}_{\mathbf{0}} \cdot \boldsymbol{\rho}_{\mathbf{0}}\right)
$$

Where, $\boldsymbol{\eta}_{\boldsymbol{r}}$ is the relative viscosity (dimensionless), $\boldsymbol{t}$ is the run-time of the sample (s), $\boldsymbol{\rho}$ is the density $\left(\mathrm{g} . \mathrm{cm}^{-3}\right)$ of the sample, while $\boldsymbol{t}_{\boldsymbol{0}}(\mathrm{s})$ and $\boldsymbol{\rho}_{\mathbf{0}}\left(\mathrm{g} . \mathrm{cm}^{-3}\right)$ is the time and density of the pure solvent. It is possible to find the specific viscosity $\left(\boldsymbol{\eta}_{s p}\right)$ from the relative viscosity by equation (2):

$$
\eta_{s p}=\eta_{r}-1
$$

Where, $\boldsymbol{\eta}_{\boldsymbol{r}}$ is the relative viscosity and $\boldsymbol{\eta}_{\boldsymbol{s}}$ is the specific viscosity (dimensionless).

Dividing the specific viscosity by the concentration of the solution gives the reduced specific viscosity $\left(\boldsymbol{\eta}_{\text {sp.red }}\right)$ represented by Equation (3):

$$
\boldsymbol{\eta}_{\text {sp.red }}=\boldsymbol{\eta}_{\text {sp }} / \boldsymbol{C}
$$

Where, $\eta_{s p}$ is the specific viscosity (dimensionless), $\eta_{s p . r e d}$ is the reduced specific viscosity $\left(\mathrm{cm}^{3} \cdot \mathrm{g}^{-1}\right)$ and $\boldsymbol{C}$ is the solution concentration $\left(\mathrm{g} \cdot \mathrm{cm}^{-3}\right)$. Dividing the natural logarithm of the relative viscosity $\left(\boldsymbol{\eta}_{\mathbf{r}}\right)$ by concentration $(\mathbf{C})$ of the solution, obtained the inherent viscosity $\left(\boldsymbol{\eta}_{\text {in }}\right)$ by equation (4):

$$
\boldsymbol{\eta}_{\text {in }}=\operatorname{Ln}\left(\boldsymbol{\eta}_{\boldsymbol{r}}\right) / \boldsymbol{C}
$$

Where $\eta_{i n}$ is the inherent viscosity $\left(\mathrm{cm}^{3} \cdot \mathrm{g}^{-1}\right)$, Ln $\left(\eta_{\mathbf{r}}\right)$ corresponds to the natural logarithm of reduced viscosity (dimensionless) and $\boldsymbol{C}$ is the concentration of the solution $\left(\mathrm{g} . \mathrm{cm}^{-}\right.$ $\left.{ }^{3}\right)$.

The intrinsic viscosity of polymeric solution can be found from the slope of the equation of the line, obtained from the graphic extrapolation to a concentration equal to zero, using the specific viscosity reduced $\left(\boldsymbol{\eta}_{\boldsymbol{s p} \text {.red }}\right)$ and/or the inherent viscosity $\left(\boldsymbol{\eta}_{\boldsymbol{i n}}\right)$.

\subsection{Mark-Houwink equation.}

The relationship of the polymer, solvent and temperature, is known as the MarkHouwink-Sakurada equation, or more commonly, the Mark-Houwink equation represented by Eqs. (5) and (6) [37-41]:

$$
\left[\eta_{\text {sp.red }}\right]=K \cdot(M v)^{\alpha}
$$

and

$$
\left[\eta_{\text {in }}\right]=K \cdot(M v)^{\alpha}
$$


Where $\left(\boldsymbol{\eta}_{\text {sp.red }}\right)$ and $\left(\boldsymbol{\eta}_{\text {in }}\right)$ are the viscosities $\left(\mathrm{cm}^{3} \cdot \mathrm{g}^{-1}\right), \boldsymbol{K}$ is related to the solvent/polymer interaction, $\boldsymbol{\alpha}$ is related to the geometry of the polymer and $\boldsymbol{M v}$ corresponds to the average viscosimetric molecular mass.

Whereas the intrínsec viscosity for PEG is the result of the equation of the line generated by graphical extrapolation of the viscosities $\left(\boldsymbol{\eta}_{\boldsymbol{s p} . r e d}\right)$ and $\left(\boldsymbol{\eta}_{\boldsymbol{i n}}\right)$, it is possible to estimate parameters " $K$ " and " $\alpha$ " of the Mark-Houwink equation, these coefficients are constant for a given system involving polymer/solvent/temperature.

\subsection{Activation energy (Ea).}

The temperature dependence of any constant rate is given by the Arrhenius relation, which provides the basis of the relationship between the activation energy and the rate at which the reaction proceeds [42]. How bigger the activation energy, the slower the reaction because it increases the difficulty for the process to occur, and the lower the activation energy, the lower the energy barrier, the more effective collisions and, therefore, a faster reaction. The relationship of the viscosity and temperature can be described by an Arrhenius type equation from equation (7):

$$
\left[\eta_{\text {sp.red }}\right]=x \cdot \exp ^{(-E a / R . T)}
$$

Where, $\boldsymbol{\eta}_{\boldsymbol{s} \text {.red }}$ is the constant rate of reduced specific viscosity $\left(\mathrm{cm}^{3} \cdot \mathrm{g}^{-1}\right), \boldsymbol{E} \boldsymbol{a}$ is the energy of activation $\left(\mathrm{kJ} \cdot \mathrm{mol}^{-1}\right), \boldsymbol{R}$ is the gas constant $\left(0.008314 \mathrm{~kJ} \cdot \mathrm{mol}^{-1} \cdot \mathrm{K}^{-1}\right), \boldsymbol{T}$ is the absolute temperature $(\mathrm{K})$, and $\boldsymbol{x}$ the pre-exponential factor independent or approximately independent of temperature.

From the concentrations and temperatures studied to obtain the activation energy $(\boldsymbol{E} \boldsymbol{a})$ of polyethylene glycol, the predicted data were analyzed versus the estimated data by means of the statistical indicator square root of the mean square error (RMSE). The RMSE is used to aggregate the magnitudes of the errors in predictions for various times into a single measure of predictive power, is a measure of accuracy, to compare forecasting errors of different models for a particular dataset and not between datasets, as it is scale-dependent represented by Equation (8):

$$
R M S E=\sqrt{\sum_{i=1}^{N} \frac{\left(\eta_{e x p}-\eta_{c a l}\right)^{2}}{N}}
$$

The square root of the mean square error (RMSE) quantifies the dispersion of the analyzed and estimated values, in which $\boldsymbol{N}$ corresponds to the number of temperature variables, $\left(\boldsymbol{\eta}_{\text {exp }}\right)$ the experimental data from viscosity and $\left(\boldsymbol{\eta}_{\text {cal }}\right)$ the calculated viscosity data. The parameters were estimated using the software Statistica (version 5.0 - StatSoft).

\section{Results and Discussion}

\section{1. $X$-ray diffraction study $(X R D)$.}

X-ray diffraction (XRD) enables the characterization of a polymer's crystalline structure, which occurs due to each crystalline solid having its unique pattern for their identification. Figure 1 presents the X-Ray diffractograms of PEG 1500, 4000, 6000, 8000 e 10000 (Da). 


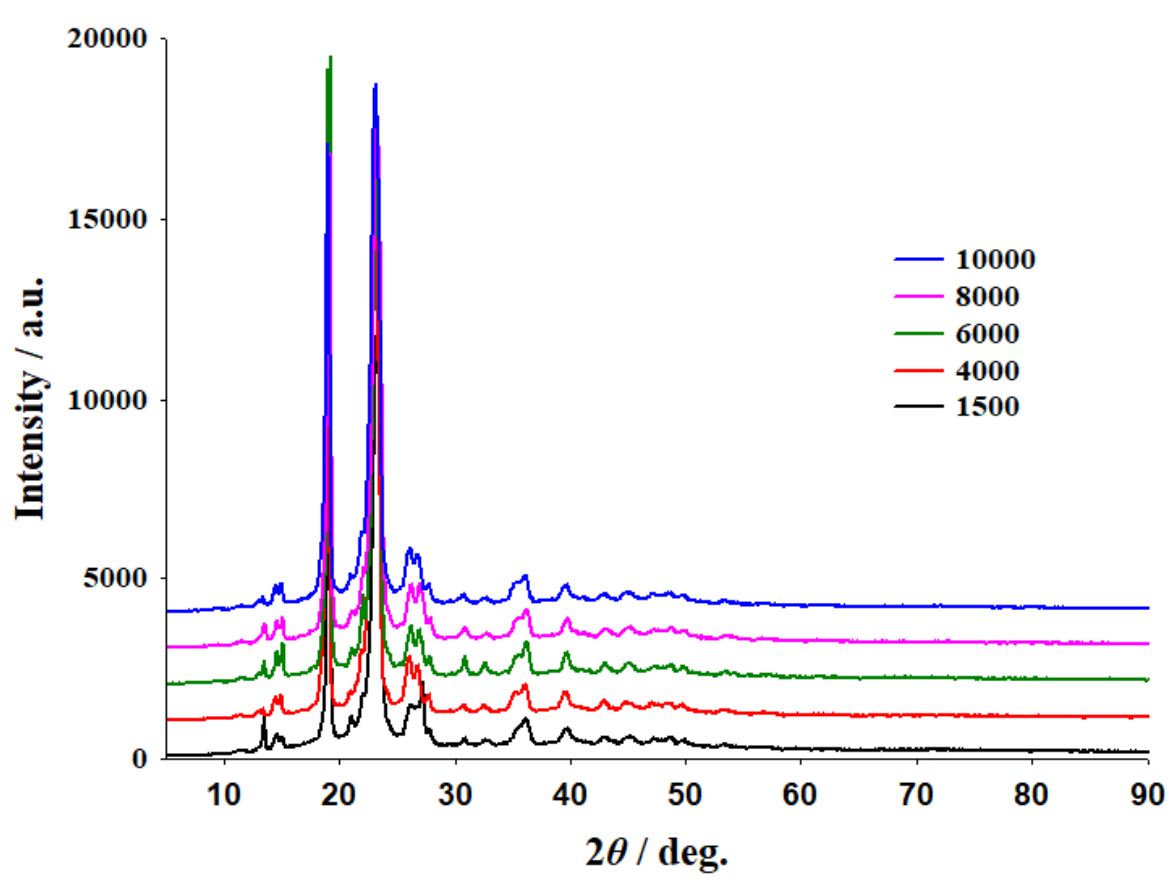

Figure 1. X-Ray diffractograms superimposed the PEG samples.

The X-ray spectra for the different molecular mass of PEG were very similar, with prevailing peaks at an angle of $2 \theta$ degrees (deg) at approximately $19^{\circ}$ and $23^{\circ}$. Similar results were obtained by Patil and Gaikwad [43], which obtained peaks with intensity in $2 \theta$ of $19.3^{\circ}$ and $23.4^{\circ}$, representing qualitative data, serving only for comparison, in order to verify if the polymers had the same standards because they were from different suppliers.

\subsection{PEG density study.}

The crystallinity gives the polymers high density, high strength and low hardness due to the packaging of macromolecules. The densities of the different molecular mass of PEG decreased with high temperature and increased with high concentration. The decrease in density with temperature can be attributed to the great mobility of liquid molecules, which causes volume expansion and the decrease of molecular interactions at higher temperatures. Densities in PEG aqueous solutions with molecular mass between 1500 and 10000 (Da) at the same temperature presented values between 0.98693 and $1.01517\left(\mathrm{~g} . \mathrm{mL}^{-1}\right)$. The densities were substantially independent of the molecular mass of the PEG.

\subsection{Determination of intrínsic viscosity.}

From the experimental data of density and run time for the different molecular mass of PEG and different temperatures, it was possible to calculate the relative viscosity (equation 1), specific viscosity (Equation 2) and reduced specific viscosity (Equation 3). The intrinsic viscosities were determined by adjusting the straight equation through linear and nonlinear regression in Figure 2. The intrinsic viscosities for each PEG at different temperatures are shown in Table 2.

According to Table 2, the intrinsic viscosities for each molecular mass of PEG decreased with increasing temperature. The increase in fluid temperature leads to increased mobility of the molecules, increasing the intermolecular spaces, promoting the decrease of the resistance to flow, with a consequent reduction in viscosity [44]. 

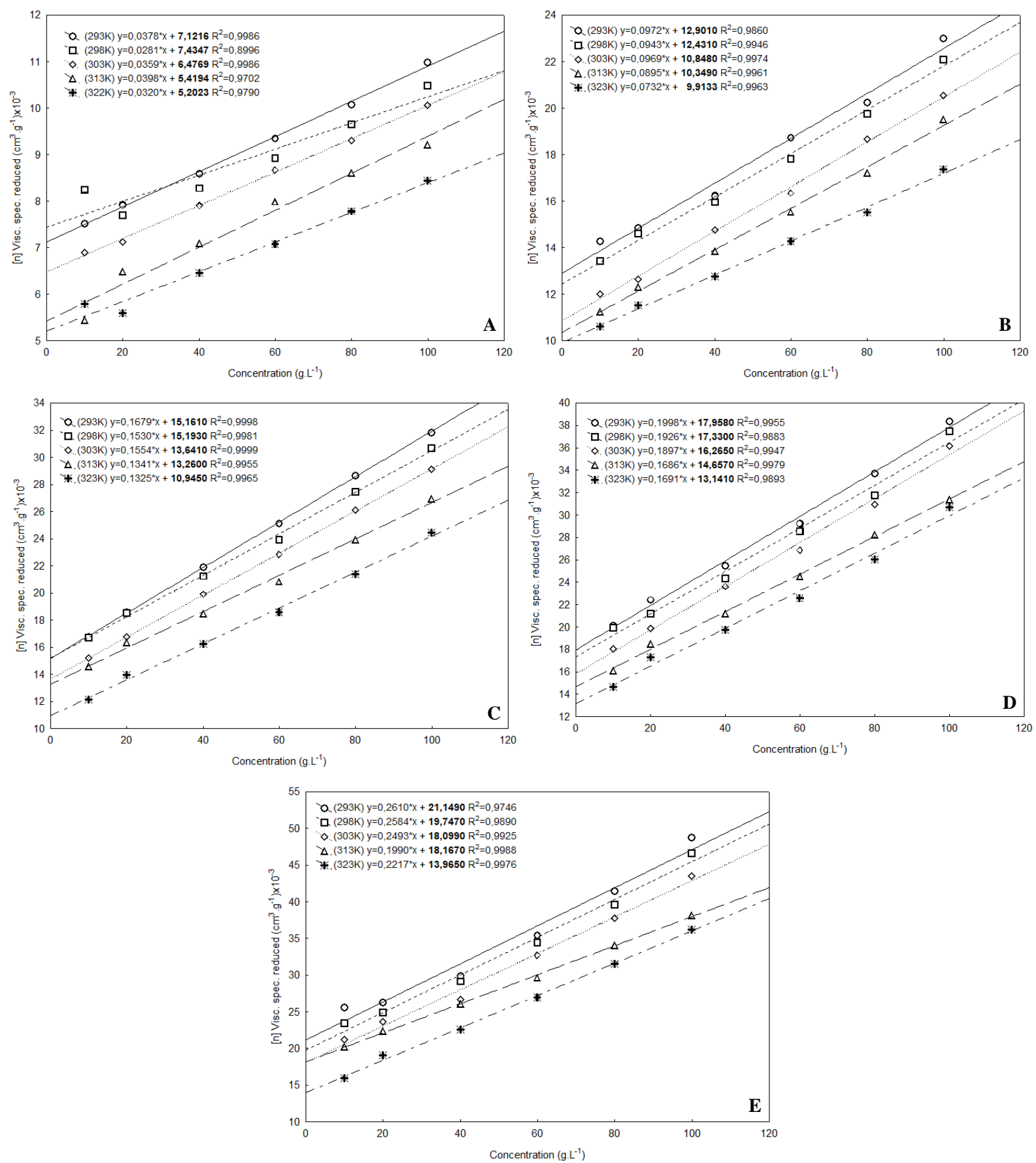

Figure 2. Adjusted straight line equation representing the intrinsic viscosity by the linear coefficient of PEG 1500 (A), PEG 4000 (B), PEG 6000 (C), PEG 8000 (D) e PEG 10000 (E).

Table 2. Intrinsic Viscosities for Different Molecular mass of PEG (1500, 4000, 6000, 8000 e 10000 Da) at different temperatures (293, 298, 303, 313 e 323 K).

\begin{tabular}{c|c|c|c|c|c}
\multirow{2}{*}{ Temperature (K) } & \multicolumn{5}{|c}{ Molecular Mass (Da) } \\
\cline { 2 - 5 } & PEG 1500 & PEG 4000 & PEG 6000 & PEG 8000 & PEG 10000 \\
\hline 293 & 7.1216 & 12.9010 & 15.1610 & 17.9580 & 21.1490 \\
\hline 298 & 7.4347 & 12.4310 & 15.1930 & 17.3300 & 19.7470 \\
\hline 303 & 6.4769 & 10.8480 & 13.6410 & 16.2650 & 18.0990 \\
\hline 313 & 5.4194 & 10.3490 & 13.2600 & 14.6570 & 18.1670 \\
\hline 323 & 5.2023 & 9.9133 & 10.9450 & 13.1410 & 13.9650
\end{tabular}

Intrinsic viscosity is a characteristic amount of a polymer. It represents an increase in the viscosity of the solution when the concentration is raised to a certain level. As expected, a polymer molecule with a larger dimension has a higher intrinsic viscosity [40]. 
The " $\mathrm{K}$ " values increased with increasing temperature, in compensation, the values obtained for $\alpha$ decreased how can be observed in Table 3 .

Table 3. Constants $\boldsymbol{K}$ and $\boldsymbol{\alpha}$ estimated estimated at different temperatures.

\begin{tabular}{c|c|c|c} 
Temperature $(\mathbf{K})$ & $\boldsymbol{K}\left(\mathbf{c m}^{\mathbf{3}} \cdot \mathbf{g}^{-\mathbf{1}} \mathbf{)} \mathbf{1} \mathbf{1 0}^{-\mathbf{3}}\right.$ & $\boldsymbol{\alpha}$ & $\mathbf{R}^{\mathbf{2}}$ \\
\hline 293 & 0.047745 & 0.662086 & 0.98968 \\
\hline 298 & 0.046828 & 0.659350 & 0.98179 \\
\hline 303 & 0.056395 & 0.628964 & 0.99606 \\
\hline 313 & 0.098171 & 0.563051 & 0.99270 \\
\hline 323 & 0.298291 & 0.418492 & 0.99449
\end{tabular}

According to Table 3, is possible observe that value of " $\boldsymbol{K}$ " is affected by the molecular mass distribution, already " $\boldsymbol{\alpha}$ " is related to the conformation of the polymer in solution. For flexible polymers in a good solvent, the values of " $\alpha$ " are found between 0.5 and 0.8. For polymers with many branching, values are below 0.5 already in rigid polymers, the values of " $\alpha$ " can be superior to 1 [45]. The molecular mass does not change with temperature, what changes are the hydrodynamic properties of the system except when connection breaks occur or aggregation of macromolecules [46].

Moreira et al. [47] used values of " $K$ " and " $\alpha$ " obtained by capillary viscosimetry in comparison to values obtained by the instrumental technique of gel permeation chromatography (GPC), where they analyzed samples of poly (p-acetoxystyrene) diluted in tetrahydrofuran (THF) at $298 \mathrm{~K}$. The values were similar for both techniques, whereas for viscosimetric analysis $K=1.442 \times 10^{-2}$ g.mL $\mathrm{mL}^{-1}$ and $\boldsymbol{\alpha}=0.695$, respectively, compared to tabulated values of $K=1.10 \times 10^{-2} \mathrm{~g} \cdot \mathrm{mL}^{-1}$ and $\boldsymbol{\alpha}=0.725$ determined by GPC, demonstrating that both techniques reproduce representative results. Thus, the use of a capillary viscosimeter is an efficient technique in the analysis of polymers in solution.

Studies developed by Mansuelli [46] involving the parameters of the Mark-Houwink equation with aqueous solutions of biopolymers (Xanthan, Pectin and Gelatin), a decrease in the parameter values " $\alpha$ " was observed when evaluated in relation to temperature, which is related to the affinity of the macromolecule to the solvent, is it becomes more hydrophilic. While for the values of " $\boldsymbol{K}$ " little difference was observed in relation to temperature and concluded that " $\boldsymbol{K}$ " is independent of temperature. However, it can be seen in Table 3, that is the closest temperature ranges, there was little variation in the values of " $K$ ", and as the temperature variation is more significant for "K", ranging from 0.047745 a $293 \mathrm{~K}$ to 0.298291 at $323 \mathrm{~K}$ making the values of " $\boldsymbol{K}$ " dependent on temperature.

\subsection{Activation energy study.}

The viscosity parameter used in the Mark-Houwink equation allows us to evaluate the interaction between a solution of the polymer and temperature because the polymeric macromolecule changes the hydrodynamic radius with the type of solution and temperature, by changing the flexibility of its chain, can be observed the behavior of the polymers studied in Figure 3.

The activation energy indicates the influence of the change in viscosity with increasing temperature [48]. Through the activation energy $\left(\mathrm{kJ}^{\mathrm{m}} \mathrm{mol}{ }^{-1}\right)$ calculated by the Arrhenius type equation, it is possible to observe the relationship between the solute and the solvent.

In Table 4 is possible to observe the in relation between the Activation Energy and the molecular mass, because the higher the activation energy the slower the reaction and the lower the activation energy, more effective collisions and therefore, a faster reaction. 

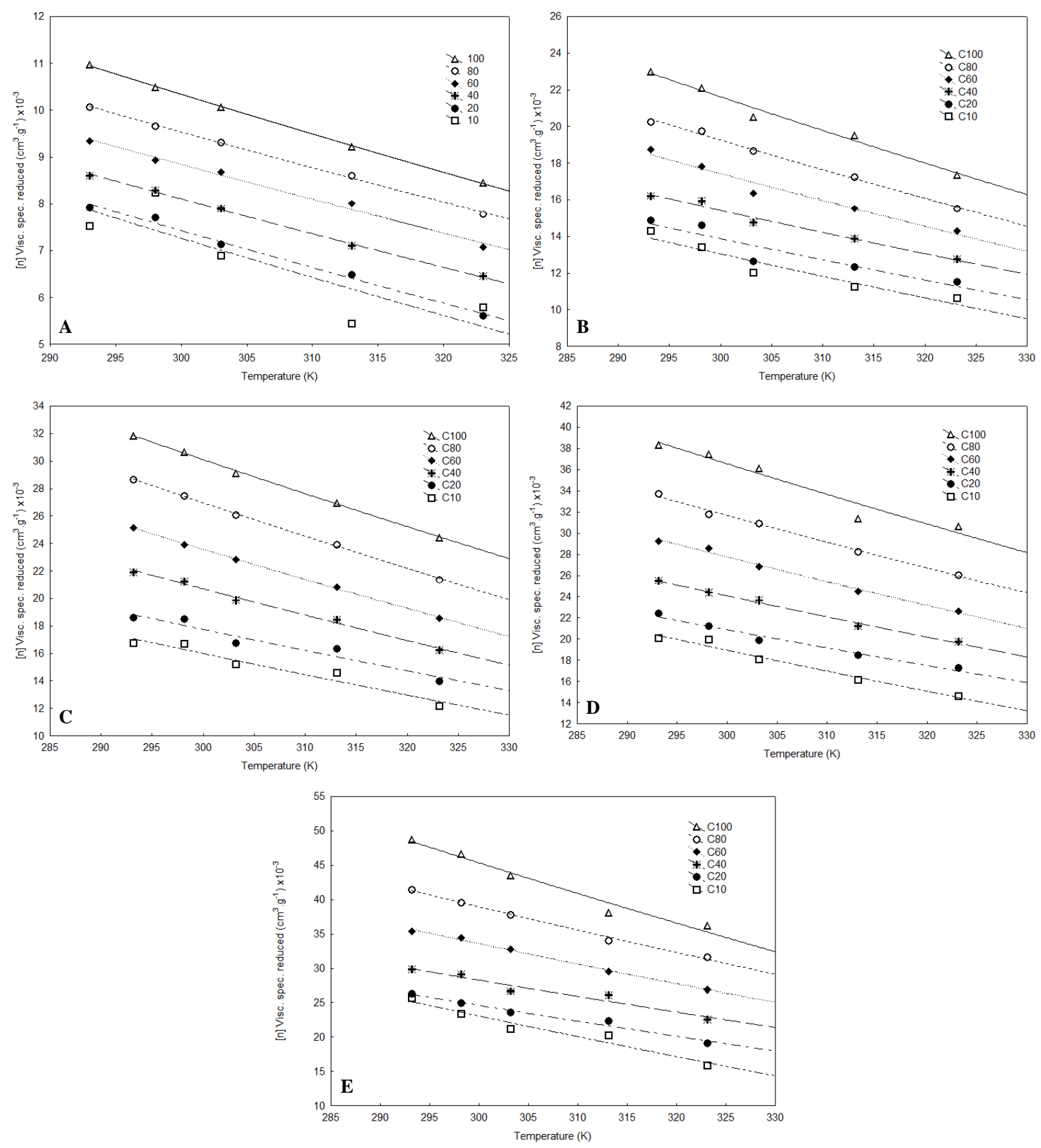

Figure 3. Relation of the viscosity of each concentration with the temperature for the PEG 1500 (A), PEG 4000 (B), PEG 6000 (C), PEG 8000 (D) e PEG 10000 (E).

Table 4. Activation energy ( $\boldsymbol{E a})$ for different molecular mass of PEG.

\begin{tabular}{c|c|c|c|c|c}
\multirow{2}{*}[\mathbf{C}]{} & PEG 4000 & PEG 6000 & PEG 8000 & PEG 10000 \\
\cline { 2 - 6 } & PEG 1500 & PJ.mol & \multicolumn{1}{c}{ (1500 } \\
\hline 10 & 10.0246 & 8.0691 & 7.9870 & 8.8194 & 7.2906 \\
\hline 20 & 8.9477 & 7.0273 & 7.1343 & 6.9229 & 6.9671 \\
\hline 40 & 7.6818 & 6.4987 & 7.7419 & 6.8708 & 7.3504 \\
\hline 60 & 6.9878 & 7.1162 & 7.8043 & 7.0210 & 7.2653 \\
\hline 80 & 6.6183 & 6.9990 & 7.5431 & 6.6380 & 8.3827
\end{tabular}

The relationship between the experimental and calculated data with the statistical indicator. Although in different concentrations, the smaller dispersion was obtained for PEG $1500(\mathrm{RMSE}=0.0278)$ and the largest for PEG $10000(\mathrm{RMSE}=0.7108)$, indicating that the best fit was for the PEG 1500. 
Canteri et al. [49], studying Ea of pectin, obtained results of approximately 20 times greater than PEG, such effect may be related to its chemical structure, for pectin can be considered a colloidal substance, not necessarily water-soluble, and thus increasing viscosity by the formation of gels. The rheological behavior of jaboticaba pulp compared to low viscosity materials such as apple juice with and without pectin, and viscosity of pear puree and açai, obtained activation energy values $\left(\mathrm{Ea}=6.28 \mathrm{~kJ}_{\mathrm{mol}}{ }^{-1}\right)$, because the greater the $\mathrm{Ea}$, the greater the influence of temperature [50]. The activation energy is influenced by the rate of heat transfer that is influenced by the particle size. The lower the particle sizes, the higher the heat transfer rate and the lower the activation energy.

The polymer and solvent interaction is a relative phenomenon because it refers to intermolecular interactions. For PEG in different molecular mass did not obtain an activation energy pattern because external factors with ambient temperature and atmospheric pressure may have influenced. For PEG 10000 was obtained the largest $\mathrm{Ea}=11.2906 \mathrm{~kJ} \mathrm{~mol}^{-1}$, and the smallest $\mathrm{Ea}=6.49873 \mathrm{~kJ}^{\mathrm{mol}}{ }^{-1}$ for PEG 4000, confirming the hypothesis of external interference.

Studies involving activation energy using viscosity in relation to the temperature in a pectin solution obtained $\mathrm{Ea}=25.17 \mathrm{~kJ} \cdot \mathrm{mol}^{-1}$, while for the pure solvent $\mathrm{Ea}=16.91 \mathrm{~kJ} . \mathrm{mol}^{-1}$. When a good solvent is available for complete dilution of the polymer, the increase in temperature will result in the decrease of the intrinsic viscosity and the polymer chain will be less, because there is an increase of the entropy with the increase of the temperature, being that the Ea of the solute is greater than the Ea of the solvent [51].

\section{Conclusions}

The objective of this work was to estimate the parameters " $\boldsymbol{K}$ " and " $\boldsymbol{\alpha}$ " of the MarkHouwink equation for the polyethylene glycol polymer in five different average molecular mass from the viscosity obtained by the Cannon-Fenske Routine Capillary Viscosimeter. The Viscosimetry by the capillary allowed to obtain significant results for the estimation of the parameters " $\boldsymbol{K}$ " and " $\boldsymbol{\alpha}$ ", where what, with increasing temperature, an increase of " $\boldsymbol{K}$ " and a decrease of " $\alpha$ " was obtained, representing a correlation coefficient greater than $98 \%$.

Intrinsic viscosity is the measure of the molecular density of the polymer chains in solution. The tighter the chains wind up in solution, the lower the intrinsic viscosity and the higher the density. The intrinsic viscosity showed a linear correlation for PEG, that such feats may be related to the conformation and distribution of the polymer structure. As " $\alpha$ " is between 0.4 e 0.7 , related to the confirmation of the polymer, thus suggesting that polyethylene glycol behaves flexibly as an extended or linear conformation when having $\alpha$ values are between 0.5 and 0.8. The values of " $\boldsymbol{K}$ " are dependent on the interaction between the type of solvent and the polymer, which is also dependent on the working temperature.

\section{Funding}

This study was financed by CAPES, Brazil [Financial Code 001].

\section{Acknowledgments}

The authors thank the National Council for Scientific and Technological Development (CNPq), Coordination for the Improvement of Higher Education Personnel (CAPES), and Research Support Foundation of the State of Rio Grande do Sul (FAPERGS). 


\section{Conflicts of Interest}

The authors declare no conflict of interest.

\section{References}

1. Food \& Drug Adiministration (FDA, U.S.) https://www.accessdata.fda.gov/scripts/cder/iig/index.cfm (accessed March 10, 2021).

2. D'souza, A.A.; Shegokar, R. Polyethylene glycol (PEG): a versatile polymer for pharmaceutical applications. Expert Opinion on Drug Delivery 2016, 13, 1257-1275, https://doi.org/10.1080/17425247.2016.1182485.

3. Punitha, S.; Uvarani, R.; Arputham, P.; Nithiyanantham, S. Physico-Chemical Studies on Aqueous Solutions of (Amantadine and Oseltamivir) with PEG, Maltodextrin and SLS Binary Complex Formation. Letters in Applied NanoBioScience 2021, 10, 1950-1958, https://doi.org/10.33263/LIANBS101.19501958.

4. Kakkar, S.; Karuppayil, S.M.; Raut, J.S.; Giansanti, F.; Papucci, L.; Schiavone, N.; Kaur, I.P. Lipidpolyethylene glycol based nano-ocular formulation of ketoconazole. International Journal of Pharmaceutics 2015, 495, 276-289, http://dx.doi.org/10.1016/j.ijpharm.2015.08.088.

5. Shatz, W.; Hass, P.E.; Peer, N.; Paluch, M.T.; Blanchette, C.; Han, G.; Sandoval, W.; Morando, A.; Loyet, K.M.; Bantseev, V.; Booler, H.; Crowell, S.; Kamath, A.; Scheer, J.M.; Kelley, R.F. Identification andcharacterization of an octameric PEG-protein conjugate system for intravitreal long-acting delivery to the back of the eye. PLOS ONE 2019, 14, 1-20, https://doi.org/10.1371/journal.pone.0218613.

6. Reboredo, C.; González-Navarro, C.J.; Martínez-Oharriz, C.; Martínez-López, A.L.; Irache, J.M. Preparation and evaluation of PEG-coated zein nanoparticles for oral drug delivery purposes. International Journal of Pharmaceutics 2021, 597, 1-9, https://doi.org/10.1016/j.jpharm.2021.120287.

7. Sujitha, S.; Dinesh, P.; Rasool, M. Berberine encapsulated PEG-coated liposomes attenuate Wnt1/ $\beta$-catenin signaling in rheumatoid arthritis via miR-23a activation. European Journal of Pharmaceutics and Biopharmaceutics 2020, 149, 170-191, https://doi.org/10.1016/j.ejpb.2020.02.007.

8. Melo, M.N.; Pereira, F.M.; Rocha, M.A.; Ribeiro, J.G. Junges, A.; Monteiro, W.F.; Diz, F.M.; Ligabue, R.A.; Morrone, F.B.; Severino, P.; Fricks, A.T. Chitosan and chitosan/PEG nanoparticles loaded with indole-3carbinol: Characterization, computational study and potential effect on human bladder cancer cells. Materials Science and Engineering: C 2021, 124, 1-14, https://doi.org/10.1016/j.msec.2021.112089.

9. Ravindran, R.S.E.; Subha, V.; Ilangovan, R. Silver nanoparticles blended PEG/PVA nanocomposites synthesis and characterization for food packaging. Arabian Journal of Chemistry 2020, 13, 6056-6060, https://doi.org/10.1016/j.arabjc.2020.05.005.

10. Severo, C.; Anjos, I.; Souza, V.G.L.; Canejo, J.P.; Bronze, M.R.; Fernando, A.L.; Coelhoso, I.; Bettencourt, A.F.; Ribeiro, I.A.C. Development of cranberry extract films for the enhancement of food packaging antimicrobial properties. Food Packaging and Shelf Life 2021, 28, 100646, https://doi.org/10.1016/j.fpsl.2021.100646.

11. Shtenberg, Y.; Goldfeder, M.; Schroeder, A.; Bianco-Peled, H. Alginate modified with maleimide-terminated PEG as drug carriers with enhanced mucoadhesion. Carbohydrate Polymers 2017, 175, 337-346, https://doi.org/10.1016/j.carbpol.2017.07.076.

12. Khan, A.; Kumar Sahu, N. Folate encapsulation in PEG-diamine grafted mesoporous Fe3 O4 nanoparticles for hyperthermia and in vitro assessment. IET Nanobiotechnol. 2020, 14, 881-888, https://doi.org/10.1049/iet-nbt.2020.0101.

13. Chen, Y.; Li, X.; Gao, J.; Yang, M.; Liu, Y.; Liu, Y.; Tang, X. Carbon layer-modified mesoporous silica supporter for PEG to improve the thermal properties of composite phase change material. J Mater Sci 2021, 56, 5786-5801, https://doi.org/10.1007/s10853-020-05638-8.

14. Sun, X.; Yi, M.; Feng, B.; Liu, R.; Sun, L.; Zhai, L.; Cao, H.; Zou, C. Shape-stabilized composite phase change material PEG@TiO2 through in situ encapsulation of PEG into 3D nanoporous TiO2 for thermal energy storage. Renewable Energy 2021, 170, 27-37, https://doi.org/10.1016/j.renene.2021.01.114.

15. Mousa, E.; Hafez, Y.; Nasr, G.M. Optical Study on PVA/PEG Blend Doped with Nano-Silica. Journal of Elec Materi 2021, 50, 2594-2604, https://doi.org/10.1007/s11664-021-08785-z.

16. Begun, S.K.; Ratna, S.A.; Clarke, R.J.; Ahmed, M.S. Excess molar volumes, refractive indices and transport properties of aqueous solutions of poly(ethylene glycol)s at (303.15-323.15) K. Journal of Molecular Liquids 2015, 202, 176-188, https://doi.org/10.1016/j.molliq.2014.12.025. 
17. Shazali, S.S.; Amiri, A.; Zubir, M.N.M.; Rozali, S.A.; Zabri, M.Z.; Sabri, M.F.M. Colloidal stability measurements of graphene nanoplatelets covalently functionalized with tetrahydrofurfuryl polyethylene glycol in different organic solvents. Current Applied Physics 2018, 18, 209-219, https://doi.org/10.1016/j.cap.2017.10.007.

18. Drumond, W.S.; Wang, S.H.; Mothé, C.G. Synthesis and characterization of poly(lactic acid-b-ethylene glycol) copolymer. Polímeros 2004, 14, 74-79, http://dx.doi.org/10.1590/S0104-14282004000200009.

19. Gao, H.; Konstantinov, I.A.; Arturo, S.G.; Broadbelt, L.J. On the modeling of number and weight average molecular weight of polymers. Chemical Engineering Journal 2017, 327, 906-913, https://doi.org/10.1016/j.cej.2017.06.131.

20. Yatskovskaya, O.V.; Baklanova, O.N.; Gulyaeva, T.I.; Drozdov, V.A.; Gorbunov, V.A. The effect of polyethylene glycol molecular weight on characteristics of the porous structure of silica materials. Protection of Metals and Physical Chemistry of Surfaces 2013, 49, 216-221, https://doi.org/10.1134/S2070205112060196.

21. Mech, D.; Sangwai, J.S. Effect of molecular weight of polyethylene glycol (PEG), a hydrate inhibitive waterbased drilling fluid additive, on the formation and dissociation kinetics of methane hydrate. Journal of Natural Gas Science and Engineering 2016, 35, 1441-1452, https://doi.org/10.1016/j.jngse.2016.06.020.

22. Plisko, T.V.; Bildyukevich, A.V.; Usosky, V.V.; Volkov, V.V. Influence of the concentration and molecular weight of polyethylene glycol on the structure and permeability of polysulfone hollow fiber membranes. Petroleum Chemistry 2016, 56, 321-329, https://doi.org/10.1134/S096554411604006X.

23. Wang, T.; Guo, Y.; He, Y.; Ren, T.; Yin, L.; Fawcett, J.P.; Gu, J.; Sun, H. Impact of molecular weight on the mechanism of cellular uptake of polyethylene glycols (PEGs) with particular reference to P-glycoprotein. Acta Pharmaceutica Sinica B 2020, 10, 2002-2009, https://doi.org/10.1016/j.apsb.2020.02.001.

24. Marcos, M.A.; Lugo, L.; Ageev, S.V.; Podolsky, N.E.; Cabaleiro, D.; Postnov, V.N.; Semenov, K.N. Influence of molecular mass of PEG on rheological behaviour of MWCNT-based nanofluids for thermal energy storage, Journal of Molecular Liquids 2020, 318, 1-11, https://doi.org/10.1016/j.molliq.2020.113965.

25. Cai, C.; Bao, Y.; Jin, Y.; Li, F.; Pang, Y.; Lou, H.; Qian, Y.; Qiu, X. Preparation of high molecular weight pH-responsive lignin-polyethylene glycol (L-PEG) and its application in enzymatic saccharification of lignocelluloses. Cellulose 2020, 27, 755-767, https://doi.org/10.1007/s10570-019-02800-7.

26. Singh, S.; Maurya, I.C.; Srivastava, P.; Bahadur, L. Synthesis of nanosized TiO2 using different molecular weight polyethylene glycol (PEG) as capping agent and their performance as photoanode in dye-sensitized solar cells. J Solid State Electrochem 2020, 24, 2395-2403, https://doi.org/10.1007/s10008-020-04768-y.

27. Moradkhannejhad, L.; Abdouss, M.; Nikfarjam, N.; Shahriari, M.H.; Heidary, V. The effect of molecular weight and content of PEG on in vitro drug release of electrospun curcumin loaded PLA/PEG nanofibers. Journal of Drug Delivery Science and Technology 2020, 56, 1-11, https://doi.org/10.1016/j.jddst.2020.101554.

28. Faradilla, R.H.F.; Lee, G.; Sivakumar, P.; Stenzel, M.; Arcot, J. Effect of polyethylene glycol (PEG) molecular weight and nanofillers on the properties of banana pseudostem nanocellulose films. Carbohydrate Polymers 2019, 205, 330-339, https://doi.org/10.1016/j.carbpol.2018.10.049.

29. Sun, G.; Zhang, X.Z.; Chu, C.C. Effect of the molecular weight of polyethylene glycol (PEG) on the properties of chitosan-PEG-poly(N-isopropylacrylamide) hydrogels. Journal of Materials Science: Materials in Medicine 2008, 19, 2865-2872, https://doi.org/10.1007/s10856-008-3410-9.

30. Zhang, L.Y.; Yao, Y.Z.; Wang, T.; Shen, Y.; Chen, Y.H.; Zong, Z.W. Efficacy of polyethylene glycol 4000 on constipation of posttraumatic bedridden patients. Chinese Journal of Traumatology 2010, 13, 182-187, https://doi.org/10.3760/cma.j.issn.1008-1275.2010.03.010.

31. Ward, T.C. Molecular weight and molecular weight distributions in synthetic polymers. Journal of Chemical Education 1981, 58, 867-879, https://doi.org/10.1021/ed058p867.

32. Dondos, A. A new relation between the intrinsic viscosity and the molecular mass of polymers derived from the blob model: determination of the statistical segment length of flexible polymers. Polymer 2001, 42, 897901, https://doi.org/10.1016/S0032-3861(00)00481-X.

33. Billmeyer, F.W. Textbook of polymer science. 3rd ed. New York: Wiley, 1984, 208.

34. Rosen, S.L. Fundamental principles of polymeric materials. 2nd ed. New York: Wiley, 1993, 65.

35. Vega, M.P.; Lima, E.L.; Pinto, J.C. In-line monitoring of weight average molecular weight in solution polymerizations using intrinsic viscosity measurements. Polymer 2001, 42, 3909-3914, https://doi.org/10.1016/S0032-3861(00)00780-1. 
36. Mehrdad, A.; Saghatforoush, L.A.; Marzi, G. Effect of temperature on the intrinsic viscosity of poly(ethylene glycol) in water/dimethyl sulfoxide solutions. Journal of Molecular Liquids 2011, 161, 153-157, https://doi.org/10.1016/j.molliq.2011.05.013.

37. Wagner, H.L. The Mark-Houwink-Sakurada Equation for the Viscosity of Linear Polyethylene. Journal of Physical and Chemical Reference Data 1985, 14, 611-617, https://doi.org/10.1063/1.555751.

38. Wang, W.; Bo, S.; Li, S.; Qin, W. Determination of the Mark-Houwink equation for chitosans with different degrees of deacetylation. International Journal of Biological Macromolecules 1991, 13, 281-285, https://doi.org/10.1016/0141-8130(91)90027-R.

39. Chuah, H.H.; Lin-Vien, D.; Soni, U. Poly(trimethylene terephthalate) molecular weight and Mark-Houwink equation. Polymer, 2001, 42, 7137-7139, https://doi.org/10.1016/S0032-3861(01)00043-X.

40. Teraoka, I. Dynamics of dilute polymer solutions. In: Polymer Solutions: An Introduction to Physical Properties. John Wiley \& Sons, Inc., New York, 2002, 167-275, https://doi.org/10.1002/0471224510.ch3.

41. Picout, D.R.; Ross-Murphy, S.B. On the Mark-Houwink parameters for galactomannans. Carbohydrate Polymers 2007, 70, 145-148, https://doi.org/10.1016/j.carbpol.2007.03.010.

42. Ma, J.; Lei, X.; Tian, D.; Yuan, L.; Liao, C. Curing behavior and network formation of cyanate ester resin/polyethylene glycol. Journal of Applied Polymer Science 2005, 132, 1-11, https://doi.org/10.1002/app.41841.

43. Patil, M.P.; Gaikwad, N.J. Characterization of gliclazide-polyethylene glycol solid dispersion and its effect on dissolution. Brazilian Journal of Pharmaceutical Sciences 2011, 47, 161-166.

44. Deshmukh, P.S.; Manjunatha, S.S.; Raju, P.S. Rheological behaviour of enzyme clarified sapota (Achras sapota L) juice at different concentration and temperatures. Journal of Food Science and Technology 2015, 52, 1896-1910, https://doi.org/10.1007/s13197-013-1222-5.

45. Wang, J.; Huang, H.; Huang, X. Molecular weight and the Mark-Houwink relation for ultra-high molecular weight charged polyacrylamide determined using automatic batch mode multi-angle light scattering. Journal of Applied Polymer Science 2016, 133, 1-7, https://doi.org/10.1002/app.43748.

46. Mansuelli M.A. Mark-Houwink parameters for aqueous-soluble polymers and biopolymers at various temperatures. Journal of Polymer and Biopolymer Physics Chemistry 2014, 2, 37-43, https://doi.org/10.12691/jpbpc.2-2-2.

47. Moreira, J. C.; Silva, I.F.; Wang, S.H.; Balogh, D.T. Determinação das constantes K e alfa da equação de Mark-Houwink de poli(p-acetóxiestireno). Polímeros 2004, 14, 80-82, https://doi.org/10.1590/S010414282004000200010 .

48. Steffe, J.F. Rheological methods in food process engineering. Michigan: Freeman Press, 1996.

49. Canteri, M.H.G.; Moreno, L.; Wosiacki, G.; Scheer, A.P. Pectina: da matéria-prima ao produto final. Polímeros 2012, 22, 149-157, https://dx.doi.org/10.1590/S0104-1428201200500002424.

50. Sato, A.C.K.; Cunha, R.L. Influência da temperatura no comportamento reológico da polpa de jabuticaba. Food Science and Technology 2007, 27, 890-896, https://dx.doi.org/10.1590/S0101-20612007000400033.

51. Masuelli, M.A. Viscometric study of pectin. Effect of temperature on the hydrodynamic properties. International Journal of Biological Macromolecules 2011, 48, 286-291, https://doi.org/10.1016/j.ijbiomac.2010.11.014. 